\title{
NURTURING AND RETAINING CREATIVE BEHAVIOR AT THE ENTREPRENEURIAL LEVEL
}

\author{
Dipu Varghese \\ Master of Business Administration, DC School of Management and Technology, India
}

\begin{abstract}
The concept of creativity in entrepreneurship is often widely discussed as many scholars have found that Creativity and entrepreneurship are linked [40] [48]. Creativity is found to be critical throughout the journey of entrepreneurship [31]. Thus creativity cannot be considered as a onetime process linked with developing a novel business idea or establishing an ingenious business firm. It is a process that is required throughout the existence of an enterprise. This paper concentrates on how an entrepreneur can become more creative, instead of creativity of the entrepreneur, a distinction which is important. Considering the creative behavior at the entrepreneurial level, the author develops a hypothetical model to illustrate how can an entrepreneur nurture and retain creativity throughout his entrepreneurial career.
\end{abstract}

Keywords:

Creativity, Entrepreneur, Social Network, Open Problems, Openness and Courage

\section{INTRODUCTION}

The objective of this paper is to develop a hypothetical model based on the literature review and interactions with the entrepreneurs. The entrepreneurs consider creativity as a foundation stone to make their enterprises young, vibrant or energetic and to survive in this competitive world. Discussions with them gave an idea regarding how they try to maintain creativity and what are the obstacles that are present in their journey to be creative. This along with the literature review gave some insights which can be discussed in a much larger platform. These views have been filtered down to develop a hypothetical model which can better explain the ways in which an entrepreneur can nurture and retain creativity in his enterprise.

The word 'entrepreneur' which has been in use since the $16^{\text {th }}$ century is derived from the French word 'entreprendre', which bears the meaning 'to undertake' [47]. The term 'entrepreneurs' was used to refer the French men who organized and led military expeditions [60]. 'Entrepreneur' was defined by the Oxford Dictionary of 1897 as "the director or manager of a public musical institution, i.e., one who 'sets up' entertainments, especially musical performance" [8]. Schumpeter [69] considered entrepreneurs as catalysts who disturb the motionless circular flow of the economy and thereby commence and maintain the process of development and viewed entrepreneurship as an economic function. Later several proponents made attempts to understand the concept of 'entrepreneur' and 'entrepreneurship'. Cole [20] defines entrepreneur as the individual or group, who initiates, manage and/or develop a profit-oriented organization for the production and/or distribution of economic goods.

Creativity means the competence of producing new solutions in the intellectual way to solve problems. It is the ability to come up with novel and diverse viewpoints on a subject. It is the process in which the knowledge about a subject is broken down and reformed in order to put new insights into its nature. Creativity does not mean that always there should be a new idea, working upon an existing idea and improving it is also creativity [23] [46]. Being creative can be viewed as seeing the same thing as everyone else, but thinking of something different. Creativity is usually defined as the production of novel ideas that are useful and appropriate to the situation (e.g. Amabile [2], Mumford and Gustafson [55] and Sternberg [73]). Fillis and Rentschler [30] view creativity as the ability to do imaginative and non-routine things along with tradition to achieve outcomes which are profitable. Creativity has been linked to genius individuals and in business lot of people have attained gallant grade through their creative discoveries, practices and products [59], [29]. Young [64] defines creativity as the integration of advanced thinking and past which leads to actualizing the potential of an individual. Thus a person who comes out with a different idea or solution for a common problem or a common practice that is useful and appropriate to the situation can be called as creative.

\subsection{CREATIVITY AND ENTREPRENEURSHIP}

Creativity and entrepreneurship are linked [40] [48]. Entrepreneurial intentions are found to be positively related to creativity [42]. Bridge et al. [16] view creativity as an entrepreneurial characteristic. According to Fillis and Rentscheler [31] throughout the journey of entrepreneurship, creativity is found to be critical. According to them creativity of the entrepreneur stimulates business in the economy. Lee et al. [48] posits that entrepreneurship is a form of creativity and as businesses are novel and constructive it can be tagged as entrepreneurial creativity. Golshekoh et al. [35] deemed that creativity cannot be estranged from entrepreneurship. Sarri, et al. [66] highlighted the importance of training entrepreneurs in creativity. Creativity has been identified as an important factor in entrepreneurial activity and success [11]. More business opportunities have been evolved as a result of globalization and development of advanced technology, but the fact is that the market has become more crowded and competition has increased [54]. Kao [44] sees creativity as strength to survive in competition. Hence to explore these opportunities the entrepreneur must be creative so that he can get the competitive advantage for the organization which in turn provides the basis for business growth [12]. That is why Carson et al. [19] outlook creativity as a key competency in SMEs. Thus creativity enables the organizations to take benefit of opportunities which build up as the result of varying environmental circumstances [70].

Novel and useful ideas are the lifeblood of entrepreneurship [27]. Hence improvement in creativity level of an entrepreneur is essential as an organization with creative policies, strategies and products can only successfully survive in this competitive business 
world. In the history one can see lot of creative works in different domains which had changed the pace and life of human beings. Lot of inventions, discoveries, findings etc. is made by creative people in the form of new and innovative products and services in the market. Similarly there are also examples where limited thinking has hindered creativity. To give an example, Barker [9] has stated the decision of Sony to temporarily abandon the work on developing music CDs as they thought that putting 18 hours of music on a single $C D$ would lack commercial viability. As per Barker, even though they later overwhelm the problem, it was the knowledge regarding LPs that initially limited their thinking. Like this there are lots of examples in the history, both documented or undocumented, regarding limited thinking. Thus to be creative, limited thinking should be replaced with creative thinking, where the answers and solutions go beyond the early determined and society drawn track to an entirely new untraveled path.

\subsection{INTRINSIC MOTIVATION}

Majority of the theoretical models dealing with the study of entrepreneurial performance accentuate motivation as one of the key elements [45], [43], [13]. Motivation has an influence on the actions of the entrepreneur, consequently, on the quality of the entrepreneur [26]. Motivation refers to a diverse idea since it includes all the determinants of the action, how an individual behaves in a specific situation, and of course the group of factors that surrounds or influences the manifestation of that particular behavior [28] cited by [22].

When motivation is more emphasized in theoretical models of entrepreneurial performance, it becomes necessary to start with identification of the motivational factors that drive a person into entrepreneurship. These entrepreneurial motivational factors are categorized as internal "pull" factors and external "push" factors [49]. The push theories contend that negative factors such as conflicts at one's place of work, Job loss and limited alternative opportunities [37] "push" some individuals into entrepreneurship. By contrast, the pull theory suggests that sometimes a strong internal call engenders the willingness to venture without a complete guarantee of return, to take initiative in the middle of drastic perils and uncertainties [33]. Thus, a person may be externally pushed or internally pulled into the process of entrepreneurship.

Based on the above two factors (internal pull and external push) motivation can be called as intrinsic or extrinsic. When an individual performs an activity for its own sake, and derives pleasure and satisfaction from participating in it, he or she is said to be intrinsically motivated [41]. Thus intrinsic motivation relates to the internal sphere of the individual [22]. Extrinsically motivated persons perform an activity as a means to an end [41]. Extrinsic motivation belongs to the external sphere of the individual [22]. Thus the motivational dichotomy is built upon the internal or external aspect to the individual [22]. Thus extrinsic motivation has a stronger relationship with external aspects like unemployment and the individual tries to fulfill his aims in life [39] cited by [22], in the case of intrinsic motivation.

Extrinsic motivation is the situation in which entrepreneurship is initiated by the influence of external factors like conflicts at one's place of work, job loss, limited alternative opportunities etc. [37]. These factors along with other such external factors "push" some individuals into entrepreneurship. In this case it is not the individual's internal urge, but the circumstances made him to select the entrepreneurship.

Intrinsic motivation is the situation in which entrepreneurship is initiated by the need for achievement from within [53], such as the belief that the outcome of events will be influenced by an individual's effort [17], the belief in the individuals capacity to perform a task [15] etc. In this case it is the individual's internal urge alone and not the circumstances or the external factors that had made him to enter the field of entrepreneurship.

Entrepreneurs with extrinsic motivation frequently look for easier tasks, accomplish a lower level of conceptual learning, deteriorate their creativity, tend to uphold their behavior only for a short time once their extrinsic goal is obtained and are mostly lean to negative emotions [22]. Intrinsically motivated people possess higher energy levels, action orientation, and decisiveness than the externally motivated people [7]. Entrepreneurs who enter into the field of entrepreneurship because of an intrinsic interest in the work involved, rather than taking it up because of extrinsic considerations, who makes it big. Thus it can be noted that the major distinguishing factor between high-growth entrepreneur and low-growth entrepreneur is that the high-growth entrepreneurs are motivated largely by intrinsic factors. The entrepreneurs motivated by intrinsic factors will have higher potential to carry out the energizer sub function properly [39] and thereby achieve higher entrepreneurial success.

\subsection{INTRINSIC MOTIVATION AND CREATIVITY}

What type of motivation helps a person to be more creative? The building blocks of componential model of individual creativity are relevant domain-related skills, intrinsic motivation, and creativity relevant skills [1] [2]. If one lacks motivation, no amount of relevant domain-related skills and creativity relevant skills can compensate it while performing an activity [3]. The motivational constituent will inspire an individual to explore the environment and to apply relevant domain-related knowledge in new and innovative ways [3] as seen in [4]. The interactionist model of creative behavior at the individual level $[56,8]$ suggests creativity as the complex product of a person's behavior in a given situation. This interactionist model provides an integrating framework that combines important elements like personality, cognitive, and social psychology perspectives. In the individual level intrinsic motivation can influence the creative performance [56].

Intrinsic motivation is encouraging creativity but extrinsic motivation is harmful to creativity [1, 2]. Deci and Ryan [24] argue that self-determined choice or external demands initiate behaviors. Autonomous behaviors are called self-determined behaviors, which means, a situation in which a person himself experience as the initiator of his own behavior [24]. For example, a wish to be creative or a desire to achieve a goal represents internal pull for creativity. On the other side, an individual may engage in a behavior because of the external demand. Thus, jobs given to a R\&D scientist in a company, or assignments to write novels for publishers, scripts for movies or poems for a magazine or a film present external push for creativity. This simple dichotomy represents a more complex continuum that ranges from internally driven engagement to externally driven engagement. This leads to the first preposition.

Proposition 1: Intrinsically motivated entrepreneurs are highly creative than the extrinsically motivated entrepreneurs. 


\section{MODELS ON CREATIVITY}

In order to develop a hypothetical model for creativity at the entrepreneurial level, it is quite essential to revisit the existing models on creativity. Wallas model says that creativity is a four stage process - Preparation, Incubation, Illumination and verification. In the first stage he prepares himself by defining an issue and studying more about it. In the second stage this issue is kept aside until a new idea is emerged out. The process of emerging the new idea is called illumination and in the final stage he checks the new idea which is called verification. This model states that creativity is a subconscious process which cannot be directed. As per this model an illumination should happen in your mind to take up the idea into a working mode. The idea that was prepared quite early remains idle in the mind till the 'right' time comes. The arrival of the 'right' time can be considered as the spark by which he enters into the process of applying the generated idea. This model can be linked to entrepreneurial births, as most of the potential entrepreneurs have an idea and determination to jump into the process of entrepreneurship, but because of one reason or other waits for a 'right' time to start.

In Rossman's creativity model considered to be a seven step process which starts with the identification of a need. When a need is observed a close examination of that need is done and all information's that are available relating to the need is collected and analyzed to come out with possible solutions. These solutions are critically analyzed in terms of its advantages and disadvantages, so that a new idea or solution for the unmet need or problem is spurred up. This idea which was sorted out from a careful process is then experimented in the field. In this process invention of the new idea depends on the ability of a person to really come out. If that new idea is not invented out, the entire process breaks up there. When we link this model to entrepreneurship the identification of a business opportunity or an unmet need or want of a society is the primary step. These unmet needs are further analyzed to study the same in different angles. All information related to the same are gathered to come out with the best possible solution or an entirely new business idea.

1. Observation of a need

2. Analysis of the need

3. Survey of all available information relating to the need

4. Formulation of objective solutions.

5. Critical analysis of these solutions.

6. Invention of the new idea

7. Experimenting the best solution

Osborn's seven step model for creative thinking also starts with identifying a problem and subsequently collecting information or data regarding the same. In this model after the development of an idea, it remains incubated until an illumination as in the case of Wallas model. The most important point to note in this model is that the person evaluates his implemented idea in order to see whether it was a success or not. If there are some practical issues exhibited by the implanted idea. Again that issue can be taking as a problem and go through the process, until perfection is attained. This model definitely supports the constantly changing business world as newer problems and challenges frequently rise in a running business and to be a successful business man or creative business man, he or she should constantly work on the same. Thus this model can be considered as a cyclical process of creativity.

1. Orientation towards a problem

2. Gathering relevant data

3. Analysis of the collected data

4. Ideation coming up with alternative solutions to the problem

5. Incubation waiting for an illumination

6. Synthesis putting the pieces together and

7. Evaluation judging the resulting ideas.

In Koberg and Bangnall's Universal Traveler Model, the mindset of a person is important. The spirit of being creative is injected into one's vein if he accepts the situation or problem as a challenge that should be met with. Definitely entrepreneurs accept challenges and that's why researchers associate risk with entrepreneurship. This model like Osborn's seven step model for creative thinking considers creativity as a never ending cyclic process.

1. Accept the situation or problem as a challenge

2. Analyze the problem

3. Define the main issues in the problem and the goals to be achieved

4. Generate different ideas to face the problem

5. Select the best one

6. Implement the idea

7. Evaluate the idea. (Review and plan again)

Bandrowski's process for creative strategic planning starts with analysis which involves standard planning and insight development in an area followed by creative leaps in that area. Critical Judgment is conducted in the area and an action plan is developed. Later this action plan is executed and the results are monitored.

- Analysis

- Creativity

- Judgment

- Planning

- Action

As per Barron's [10] Psychic creation model, creativity is a process which involves subconscious thoughts which in turn is uncontrollable for the creator. The first stage as per this model is conception were an entrepreneurial mind set is formed within the individual. In the next stage called gestation this entrepreneurial idea is further developed and coordinated. In the third stage parturition there will be an immense urge to bring this into light and the final stage is called bringing up the baby or further development of the emerged idea.

Robert Fritz' Process for Creation starts with conception and vision. Current reality related to the area is analyzed in detail. After that an action is taken which is adjusted, learned, evaluated and again adjusted to get the right momentum to complete the process. Living with your creation makes this model cyclic as it will help to sort out the loopholes and areas that can be excelled. This will further lead into the next creative conception and vision

- Conception 
- Vision

- Current Reality

- Take Action

- Adjust, Learn, Evaluate, Adjust

- Building momentum

- Completion

- Living with your creation.

\section{DEVELOPMENT OF THE HYPOTHETICAL MODEL}

All the above discussed models agree that the entrepreneur should have relevant data or information related to any issue. The major informal sources from which this information can be collected are undoubtedly social networks. To be creative ones mindset should be focused towards that line. Only when a person sees the problem as an open one he will be able to apply a creative analysis on the same. Implementation of creative idea is the next step. For this he should have the openness and courage to explore the same.

After carefully examining the different models on creativity, the link between creativity and entrepreneurship should be examined closely. All the models simultaneously cry that creativity happens only when people collect data or information and analyze the same to come out with innovative thoughts and ideas. There should be an orientation or mindset which favors creativity. The literature say's that at the beginning of an entrepreneur's career what motivated him to enter into business is undoubtedly a point to be discussed as intrinsic motivation is encouraging creativity and extrinsic motivation is harmful to creativity $[1,2]$. Now the question lies from where an entrepreneur will get innovative ideas. It has been proved that collaboration with other people in the network will result in creation of ideas and cooperation of the network in its development will result in generating innovative ideas [61, 62]. Social networks help in fostering the ideas developed by self or obtained from some others [6]. Next question is how to handle the problems that arise as the business progresses. When an entrepreneur sees a problem as a closed one, its solutions are already present and he follows in a predefined path but when he sees problems as open, he is required to find, invent, or discover the problems [65]. All these things sound to be good in listening to but the level of acceptance of others ideas, the extent to which one can listen to others opinions or the level to which the change can be tolerated, can be called as Openness, matters a lot. Openness refers to the propensity to be creative [14] and the eagerness to alter the existing state or condition and trial with new and diverse ideas [63]. It is found that individuals who are more open will have higher creativity [72] as open individuals have broad interests and are ingenious [14]. Thus they respond to fresh ideas and collect all type of information even outside from their daily routine and think outside the common logical patterns [67]. The last thing is the courage to bear the risk. Lot of uncertainties in all dimensions is spread in the scenario. How good you are to go forward with your creative idea rather how much courageous you are matters a lot at the end. These elements which form the different steps in the creative process of entrepreneurship should be arranged sequentially in a cyclical manner as creativity is considered by most of the scientists (as seen in different models) to be a continuous process. The creative behavior of an entrepreneur should start with analyzing the current business situation. Critical analysis of the same will lead to the identification of gaps or unmet needs within the business system. Maximum information should be collected to generate apt alternatives. In this scenario an entrepreneur with wider social network will be able to squeeze into all corners to grab all available relevant information. By analyzing the collected information he should be able to generate all possible alternatives to meet the need or gap. For this he should see the problem as an open one. If he sees the situation as a closed one, he will come up with already proven or tested solutions. All the alternatives selected should be critically examined to see its effect in the business - both positive and negative. After a careful critical evaluation, the best alternative should be selected. Now the entrepreneur should have the openness to accept it and courage to implement it. After implementing evaluate the same to see whether it was successful. The new business situation should be analyzed thoroughly to see any further gaps or needs. Thus through this paper the author tries to develop a hypothetical model which can be empirically tested later to portray how an entrepreneur nurtures and retain creativity throughout his entrepreneurial career. The following part reflects the relevance of social networks, making the problems open and openness and courage to explore new ideas in this model which in turn form and justifies the cyclical model.

\section{PROCESS OF MAKING AN INTRINSICALLY MOTIVATED ENTREPRENEUR CREATIVE / MORE CREATIVE}

\subsection{WIDER SOCIAL NETWORKS}

Social capital theory deals with the ability of a person to extract benefits from their social networks [58]. In this study we examine social capital in terms of social exchange. The exchange of resources can happen through social networks. Even financial capital can be generated from social networks [50]. Here the exchange of information and how it affects the performance of an entrepreneur is taken into consideration. The duration and strength of ties build in the social network [21] can influence the flow of information and ideas between the actors. The longer and stronger ties can supplement lot of information and act as an 'information bank' where exchange of vital and crucial ideas occurs. In the network there can be "weak ties" and "close ties" [36]. Close tie include strong relationships like immediate family members and weak ties are loose relationships that are maintained in the network. Information's that are hidden, unnoticed, not easily available etc. can be provided by either strong or weak ties. So both close and weak ties should be essentially maintained by an entrepreneur to enable the unobstructed flow of information. For example one can get an idea about a latest technology in his entrepreneurial area sometimes from another entrepreneur in the association of similar business persons. The entrepreneur can get financial assistance and man power assistance at free of cost from the strong tie. Thus more weight may be given to one side. For example a financially weak person may give much importance to strong tie [21] as he can get resources at free of cost from there. Here maintaining an equal interest on both ties is very necessary 
in terms of getting ideas and information relevant for innovations in the entrepreneurial area. Thus social capital is concerned with the identification and maintenance of network relationships.

Social networks will provide decisive information that can assist in discovering an opportunity, identifying, collecting and allocating resources [38] [32]. Thus social network helps in obtaining fresh and diverse ideas, views, opinions, suggestions, contacts etc. In addition it also helps in fostering the ideas developed by self or obtained from some others [5]. Entrepreneurial decisions are recurrently arising from the advices and directions within the ties in the network [57]. The flow of asymmetrical information between entrepreneurs and the owners of resources leads to the discovery [71] of new and innovative opportunities. The significant factors required to exploit this opportunity is, of course, received from the social network [5]. It will help to evaluate, procure, allocate and utilize the resources to exploit an opportunity fruitfully. Thus opportunities can be identified and exploited at lower costs [71].

New ideas will flicker from diverse social networks. Strong and sundry social networks will pave in the flow of unrelated information from different sectors of people in the net. Collaboration with other people in the network will result in creation of ideas and co-operation of the network in its development will result in generating innovative ideas [61] [62]. Thus in social networks the idea initiated by an individual is taken by others in the network and combine their propositions to it which in turn become the source of further new ideas [52].

Sub Proposition 1: Improving the social networks will make entrepreneurs more creative.

\subsection{MAKING THE PROBLEMS OPEN}

Problems can be closed or open. For a closed problem Getzels [34] present the example of a classroom algebra problem, in which the teacher will give the equation to solve a problem and ask the students to find answer for the given question. For instance the teacher will give the equation of arithmetic mean and ask them to find average height of students in the class. In an organization, an example of a closed problem is the task given to an accountant to prepare the financial statements. To prepare a profit and loss account or balance sheet he has to follow the standards that have been provided for it. In the case of an open problem the person is required to find a solution to the problem without any such guidelines or instructions. Thus he is required to find, invent,; or discover the problems [65]. Most artistic endeavors usually symbolize open problems [25]. This leads to a bipolar model of creativity on the basis of problems which extends from closed problems to open problems. Exposure to the open problems can help an individual to develop his creativity. Logical thinking is the barrier here. Logical thinking is orbiting around a series of steps or procedures that are known already, rather than exploring a truly new path. There will be a paradigm or a set of rules and regulations that will serve as a guide while solving a problem. This scantiness of logical thinking leads to the need for creative thinking. Thus creative thinking is a method for generating insights that might not be obtained through logical thinking. When the set of rules and regulations that guide our actions changes or a paradigm shift occurs, the need for creative thinking becomes paramount. When exposed to open problems it helps an individual to break from the logical rules and approach a problem creatively.

An entrepreneur who views a problem as closed one or has a predetermined solution, is blocking or limiting his thoughts and creative solution finding ability. He always looks on what others do when they face the same problem. Rather than this angle, he should be able to view the problem or situation as an open one where he can use his creative ability. He should be able to come out from the logical thinking (what others or society demands) and start thinking about the problem in a new dimension. He should set his mind free from all possible logical solutions and make it open as an unanswered or unsolved question. Making a problem open in business is thus highly required for enabling an entrepreneur to be creative. This leads to the preposition

Sub Proposition 2: Making the problems open makes an entrepreneur more creative.

\subsection{OPENNESS AND COURAGE TO EXPLORE IDEAS}

Openness refers to the propensity to be creative [14] and the eagerness to alter the existing state or condition and trial with new and diverse ideas [63]. It is found that individuals who are more open will have higher creativity [72] as open individuals have broad interests and are ingenious [14]. Thus they respond to fresh ideas and collect all type of information even outside from their daily routine and think outside the common logical patterns [67]. This will help them to come up with a variety of new and unknown potential career opportunities [74]. Open individuals might not follow the footsteps that is already paved and established in the society but they choose a career that no one in the social environment has taken before [67].

If a person does not have the courage he will have fear. The fear will lead to doubt, doubt regarding the creative solution he found. The questions that will disturb his mental peace are "Will it work?", "What will others think?", "Will the society or market accept this?", What will happen if I fail?" etc. The ultimate result is that one will hold on or keep apart the creative solution and run along in par with the society. Here comes the importance of openness and courage. One should be open to invite, to think, to work on and to listen the different possible solutions that comes out for a business problem. After this, he should be able to come out with a unique solution to the problem. Now what is required is the courage to execute it. The doubts and fear should be thrown away and the mind should be tuned to a fully positive experimental mood to implement it. When a person lacks the courage, he himself blocks the path to creativity. So it is highly important to be open and courage enough to explore new ideas. This leads to the preposition

Sub Proposition 3: Openness and courage to explore new ideas makes an entrepreneur more creative.

\section{HYPOTHETICAL MODEL FOR IMPROVING THE CREATIVITY OF AN INTRINSICALLY ENTREPRENEUR MOTIVATED}

Intrinsically motivated entrepreneurs entered into entrepreneurship as they had purposefully chosen it as a career. 
This can be called as entrepreneurial vocation which motivates them to select this career. It is the preference for particular behaviors and actions. They possess certain traits that helps them to work on the vocation [73] [18]. Outcomes of the entrepreneurial career are strongly predicted by vocational interests [68]. Thus it is hypothesized that intrinsically motivated entrepreneurs will be more creative than the extrinsically motivated entrepreneurs. Since they are creative they always analyze the business situation and identify the needs or gaps that must be met in order to thrive for excellence. When the intrinsically motivated entrepreneur increases the width and depth of the social networks, he will get lot of information, unsolved puzzles, new ideas, and different views etc. that are related with the identified need or gap.

When he is exposed frequently to these open problems without prejudice, he will be able to break the pre-stitched or readymade solutions and will think, enquire more, work on it, rephrase it with an open mind and come out with unique, brand new ideas or alternatives. Each of the alternatives should be analyzed for seeing the positive and negative effects they can bring into the business. After a thorough examination of each alternative, select the best one with more positive impacts. The openness to accept and hope on this idea will work when he or she has the courage to explore it. This openness and courage to explore new ideas will give them confidence to implement it avoiding all the elements of doubt and fear.

Evaluate the implemented alternative and see how it contributed to meet the gap or need that was identified earlier. Analyze the business situation again as the entire system has altered due to the implementation of a newer alternative. Again the entrepreneur will be getting new experiences, new knowledge which can further lead to the formation of new gaps or needs. Thus it is a cyclical non-stop process which makes one to change, rethink, rephrase, and rejuvenate in a continuous manner. The moment one puts full stop to this cycle, the business, ideas, products, services etc. becomes stagnant in terms of creativity. To survive, to grow, to establish and at the utmost to be creative the cycle should go on and on.

\section{IMPLICATIONS FOR THEORY}

The major contribution of this paper which may have immediate implication for entrepreneurship theory is the 'creative' disparity based on motivational difference, which would imply that there is need for a fresh taxonomy of entrepreneurs, which in turn would call for a different set of variables to explain creativity of entrepreneurship on the basis of motivation. The application of creativity theory would help in identifying the factors that nurture and retain creative behavior throughout the entrepreneurial career. From this study one could try to understand why some organizations are continuously growing and why others are small, stagnant or in the path of extinction.

\section{IMPLICATIONS FOR PRACTICE}

The researchers usually study creativity by taking the entrepreneurs as a whole or the researcher does not divide the entrepreneurs based on the type of motivation. In this research, the study has been concentrated on the creativity of the intrinsically motivated entrepreneurs. It is in this respect that the hypothetical model developed has implications for those who are engaged in entrepreneurship development, especially financial institutions, entrepreneurship trainers and policy makers.



Fig.1. Improving the creativity of an intrinsically motivated entrepreneur

Based on the policies and strategies which are able to discriminate between creative and non-creative entrepreneurs, an instrument may be developed for identifying and selecting intrinsically motivated creative entrepreneurs. This instrument will be useful to financial institutions, which will help them to hand over their resources to the right hand. This is extremely important as repayment of finance provided will be disturbed when an enterprise fails. Hence at the time of sanctioning loan the entrepreneur must be properly assessed. If a reliable instrument for assessing the type of motivation and level of creativity possessed by the entrepreneur or potential entrepreneur is developed, much of the wastage can be probably avoided.

It is the policies and strategies of the entrepreneur than the environment that molds entrepreneurial behavior. So training the intrinsically motivated entrepreneurs in the respective policies and strategies of a successful creative entrepreneur will help them to take good and apt decisions when required. Training in policies and strategies helps to develop traits and enhance motivation among the entrepreneurs. Trainers can select intrinsically motivated entrepreneurs and provide further training for improving and proper utilization of social networks, to see problems as open and to inculcate the openness and courage to explore new ideas during entrepreneurship development programs. The contents of these training programs must be focusing on the above said and other similar such points raised by other related research studies.

There are various schemes for promoting entrepreneurs in different sectors. Policy-makers can evaluate these incentive schemes which they currently provide to promote entrepreneurship. These schemes sometimes attract concessiongrabbers rather than genuine entrepreneurs. In order to enjoy the incentives available for a small enterprise, the entrepreneurs may purposefully restrict the growth of the enterprise and maintain it as a small-scale enterprise. It will be extremely fruitful if the 
policy - makers are able to reorient the policies towards protecting the small enterprises which will grow further, rather than assisting the small enterprises which aims, primarily, only the incentives and artificially put a ceiling for the growth. The motivation type and the level of creativity along with other such factors generated by other research works should be considered while designing policies for promoting entrepreneurship. The criteria for eligibility of assistance should be the "internal viability" of the entrepreneur, which can be a blend of intrinsic motivation, creativity and other such factors revealed from other researches, rather than factors which are mostly external to the entrepreneur. Thus the focus of assistance will have to gradually shift from helping anyone coming with a good project to assisting intrinsically motivated creative entrepreneurs with a viable and promising project.

\section{CONCLUSIONS}

A person may be entering into entrepreneurship either through self-determined choice or because of external demands. Social networks give an entrepreneur lot of exposure and contacts which in turn helps to improve the information or knowledge level possessed by him. Internally initiated entrepreneurs use the social network in favor of his entrepreneurial vocation. When a person is put into certain situations which requires him to find, invent, or discover problems [65], he is forced or expected to be creative. Thus the best method of demanding an entrepreneur to be creative is by exposing him to open problems, where he attempts to be creative by coming out the cobwebs of unnecessary limited thinking. He will transfer from logical thinking to creative thinking. Thus a wider social network provides a broad platform upon which lot of live open problems will be exhibited and an intrinsically motivated entrepreneur because of his internal urge comes up with creative solutions. To execute this he should have the openness and courage to explore new ideas. This openness and courage will break all the cobwebs related to logical thinking and enables him to be more creative. It can be considered as a cyclical process in which he will be able to identify further information or areas to be concentrated or problems in his areas of interest from the social network and again go for creative thinking upon it.

\section{DIRECTIONS FOR FUTURE RESEARCH}

The discussions above suggest several aspects on which further research could be undertaken. They are

1. Based on the type of motivation, it is possible to develop an instrument for identifying and selecting intrinsically motivated entrepreneurs.

2. An empirical investigation with a finer measurement scale could be done in order to find whether the creativity level of intrinsically motivated entrepreneurs and extrinsically motivated entrepreneurs differ.

3. Policies and strategies of creative entrepreneurs may be different from those of non- creative entrepreneurs. A field study with a complete list of policies and strategies could be done to identify the unique one's associated to creative entrepreneurs, so that creativity at the entrepreneurial level and competitive edge acquired by an organization can be explained more accurately.
4. There could be comparative study in similar manner among different types of entrepreneurs by dividing the entrepreneurs based on the type of business they do, so that the discrepancy of creativity in different types of business can be explored.

\section{REFERENCES}

[1] Teresa M. Amabile, "The Social Psychology of Creativity", Springer, 1983.

[2] Teresa M. Amabile, "Social Psychology of Creativity: A Componential Conceptualization", Journal of Personality and Social Psychology, Vol. 45, No. 2, pp. 357-376, 1983.

[3] Teresa M. Amabile, "A Model of Creativity and Innovation in Organizations", Research in Organizational Behavior, Vol. 10, pp. 123-167, 1988.

[4] P. Eder and J. Sawyer, "The Power to be Creative at Work: Examining the Componential Model of Employee Creativity", Proceedings of Eastern Academy of Management Annual Conference, pp. 1-6, 2008.

[5] H. Aldrich and C. Zimmer, "Entrepreneurship through Social Networks", Population Perspectives on Organizations. pp. 13-28, 1986.

[6] H. Aldrich, L. Renzulli and N. Langton, "Passing on Privilege: Resources provided by Self-Employed Parents to their Self-Employed Children", Research in Social Stratification and Mobility, Vol. 16, pp. 291-317, 1998.

[7] Arie Aviram, "A Study of Factors that Influence Unemployed Persons", Journal of Employment Counseling, Vol. 43, No. 4, pp. 154-167, 2006.

[8] B.C. Tandon, "Environment and Entrepreneur", Chugh Publication, 1975.

[9] J. Barker, "Paradigms: The Business of Discovering the Future", Harper Press, 1993.

[10] Tapomoy Deb, "Strategic Approach to Human Resource Management", Atlantic Publisher, 2006.

[11] R. Baum, E.A. Locke and K. Smith, "A Multi-Dimensional Model of Venture Growth", Academy of Management Journal, Vol. 44, pp. 292-303, 2000.

[12] Chris Bilton, "Management and Creativity: From Creative Industries to Creative Management", Willey-Blackwell, 2007.

[13] K. Blawatt, "Defining the Entrepreneur: A Conceptual Model of Entrepreneurship", Proceedings of Canadian Council on Small Business and Entrepreneurship, pp. 13-37, 1995.

[14] H. Zhao and S.E. Seibert, "The Big Five Personality Dimensions and Entrepreneurial Status: A Meta-Analytical Review”, Journal of Applied Psychology, Vol. 91, No. 2, pp. 259-271, 2006.

[15] N.G. Boyd and G. Vozikis, "The Influence of Self-Efficacy on the Development of Entrepreneurial Intentions and Actions", Entrepreneurship Theory and Practice, Vol. 18, No. 4, pp. 63-77, 1994.

[16] S. Bridge, K. O’Neill and S. Cromie, "Understanding Enterprise, Entrepreneurship and Small Business", $2^{\text {nd }}$ Edition, MacMillan Press, 2003.

[17] Robert H. Brockhaus and Pamela S. Horqitz, "Psychology of the Entrepreneur", The Art and Science of Entrepreneurship, pp. 233-241, 1982. 
[18] Luigino Bruni and Alessandra Smerilli, "The Value of Vocation. The Crucial Role of Intrinsically Motivated People in Values-based Organizations", Review of Social Economy, Vol. 67, No. 3, pp. 271-288, 2009.

[19] D. Carson, S. Cromie, P. McGowan and J. Hill, "Marketing and Entrepreneurship in SMEs. An Innovative Approach", Prentice Hall, 1995.

[20] A.H. Cole, "Business Enterprise in its Social Setting", Harvard University Press, 1959.

[21] K.S. Cook and M. Whitmeyer, "Two Approaches to Social Structure: Exchange Theory and Network Analysis", Annual Review of Sociology, Vol. 18, pp. 109-127, 1992.

[22] Joaquin Guzman and F. Javier Santos, "The Booster Function and Entrepreneurial Quality: An Application to the Province of Seville", Entrepreneurship and Regional Development, Vol. 13, No. 3, pp. 211-228, 2001.

[23] J. Daniel Couger, "Creative Problem Solving and Opportunity Finding", Boyd and Fraser Publishing, 1995.

[24] E.L. Deci and R.M. Ryan, "The Support of Autonomy and the Control of Behavior", Journal of Personality and Social Psychology, Vol. 53, pp. 1024-1037, 1987.

[25] J.T. Dillon, "Problem Finding and Solving", Journal of Creative Behavior, Vol. 16, No. 2, pp. 97-111, 1982.

[26] Mark A.G. Darroch and T.A. Clover, "The Effects of Entrepreneurial Quality on the Success of Small, Medium and Micro Agribusinesses in Kwazulu-Natal, South Africa", Agrekon, Vol. 44, pp. 321-343, 2005.

[27] T.B. Ward, "Cognition, Creativity, and Entrepreneurship", Journal of Business Venturing, Vol. 19, No. 2, pp. 173-188, 2004.

[28] J.I. Velaz-Rivas, "Motivos Y Motivacion en la Empresa", Business and Economics, 1996.

[29] H.J. Eysenck, "Genius: The Natural History of Creativity", Cambridge University Press, 2008.

[30] I. Fillis and R. Rentschler, "Creative Marketing: An Extended Metaphor for Marketing in a New Age", Palgrave Macmillan, 2006.

[31] I. Fillis and R. Rentscheler, "The Role of Creativity in Entrepreneurship", Journal of Enterprising Culture, Vol. 18, No. 1, pp. 49-81, 2010.

[32] B. Uzzi, "Embeddedness in the Making of Financial Capital: How Social Relations and Networks Benefit Firms Seeking Financing", American Sociological Review, Vol. 64, No. 4, pp. 481-505, 1999.

[33] G. George, "Wealth and Poverty", New York: Basic Books, 1981.

[34] J.W. Getzels, "Problem Finding and the Inventiveness of Solutions", The Journal of Creative Behavior, Vol. 9, No. 1, pp. 12-18, 1975.

[35] F. Golshekoh, A. Hassan, P. Gholamreza, E. Mirsaladin, P. Askary and H. Alireza, "Relationship between Creativity, Grade Point Average, Achievement Motivations, Age and Entrepreneurship among University Students", Australian Journal of Basic and Applied Sciences, Vol. 4, No. 10, pp. 5372-5378, 2010.

[36] Mark S. Granovetter, "The Strength of Weak Ties", American Journal of Sociology, Vol. 78, No. 6, pp. 13601380, 1973.

[37] D.B. Greenberger and D. Sexton, "New Leadership Research Methods for the Understanding of Entrepreneurs",
Journal of Small Business Management, Vol. 26, pp. 1-7, 1988.

[38] P.G. Greene and T.E. Brown, "Resource Needs and the Dynamic Capitalism Typology", Journal of Business Venturing, Vol. 12, No. 3, pp. 161-173, 1997.

[39] J. Guzman, "Towards a taxonomy of entrepreneurial theories", International Small Business Journal, Vol. 12, No. 4, pp. 77-88, 1994.

[40] Bruce G. Whiting, "Creativity and entrepreneurship: How do they relate?", Journal of Creative Behavior, Vol. 22, pp. 178-183, 1988.

[41] Wong-On-Wing, Guo Bernard Lan and Gladie Lui, "Intrinsic and Extrinsic Motivation and Participation in Budgeting: Antecedents and Consequences", Behavioral Research In Accounting, Vol. 22, No. 2, pp. 133-153, 2010.

[42] Daniel Yar Hamidi, Karl Wennberg and Henrik Berglund, "Creativity in Entrepreneurship Education", Journal of Small Business and Enterprise Development, Vol. 15, No. 2, pp. 304-320, 2008.

[43] Lanny Herron and Richard B. Robinson Jr, "A Structural Model of the Effects of Entrepreneurial Characteristics on Venture Performance, Journal of Business Venturing, Vol. 8, No. 3, pp. 281-294, 1993.

[44] J.J. Kao, "Entrepreneurship, Creativity and Organization", Prentice-Hall, 1989.

[45] B.W. Keats and J.S. Bracker, "Toward A Theory of Small Performance: A Conceptual Model", American Journal of Small Business, Vol. 12, No. 1, pp. 42-57, 1988.

[46] Donald F. Kuratko, Jeffrey S. Horns and Michael G. Golds, "Innovation Acceleration: Transforming Organizational Thinking", Pearson, 2012.

[47] Lavanya. K. Latha and B.E.V.V.N. Murthy, "The Motives of Small Scale Entrepreneurs: An Exploratory Study", South Asian Journal of Management, Vol. 16, No. 2, pp. 92-108, 2009.

[48] Sam Youl Lee, Richard Florida and Zoltan Acs, "Creativity and Entrepreneurship: A Regional Analysis of New Firm Formation", Regional Studies, Vol. 38, No. 8, pp. 879-891, 2004.

[49] J. Liao, P.H. Welsch and D. Pisturi, "Environmental and Individual Determinants of Entrepreneurial Growth: An Empirical Examination", Journal of Enterprising Culture, Vol. 9, No. 3, pp. 253-272, 2001.

[50] Glenn C. Loury, "Why should we Care about Group Inequality?", Social Philosophy and Policy, Vol. 5, No. 1, pp. 249-271, 1987.

[51] Mathew. J. Manimala, "Entrepreneurship Theory at the Cross Roads: Paradigms and Praxis", $2^{\text {nd }}$ Edition, A.H. Wheeler Publishing Co Ltd, 1999.

[52] A. Marshall, "Principles of Economics", Macmillan Press, 1920.

[53] D.C. McClelland, "The Achieving Society", Princeton, 1961.

[54] J.S. McMullan and D.A. Shepherd, "Entrepreneurial Action and the Role of Uncertainty in the Theory of the Entrepreneur", Academy of Management Review, Vol. 31, No. 1, pp. 132-152, 2006.

[55] M.D. Mumford and S.B. Gustafson, "Creativity Syndrome: Integration, Application and Innovation", Psychological Bulletin, Vol. 103, pp. 27-43, 1988. 
[56] R.W. Woodman, J.E. Sawyer and R.W. Griffin, "Toward A Theory of Organizational Creativity", Academy of Management Review, Vol. 18, No. 2, pp. 293-321, 1993.

[57] P. Paxton, "Is Social Capital Declining in the United States? A Multiple Indicator Assessment", American Journal of Sociology, Vol. 105, No. 1, pp. 88-127, 1999.

[58] A. Portes, "Social Capital", Annual Review of Sociology, Vol. 23, pp. 1-24, 1998.

[59] G.J. Puccio, "William Duff's Eighteenth Century Examination of Original Genius and Its Relationship to Contemporary Creativity Research", Journal of Creative Behavior, Vol. 25, No. 1, pp. 1-10, 1991.

[60] Poornima M. Charantimath, "Entrepreneurship Development and Small Business Enterprise", Droling Kindersley Publishing Private Limited, 2006.

[61] S. Robinson and H.A. Stubberud, "Social Networks and Entrepreneurial Growth", International Journal of Management and Information Systems, Vol. 15, No. 4, pp. 65-70, 2011.

[62] S. Robinson and H.A. Stubberud, "Sources of Information and Cooperation for Innovation in Norway", Journal of International Business Research, Vol. 10, No. 2, pp. 79-90, 2011.

[63] Sonia Roccas, Lilach Sagiv, Shalom H. Schwartz and Ariel Knafo, "The Big Five Personality Actors and Personal Values", Personality and Social Psychology Bulletin, Vol. 28, No. 6, pp. 789-801, 2002.

[64] J.G. Young, "What is Creativity?", Journal of Creative Behavior, Vol. 19, No. 2, pp. 77-87, 1985.

[65] Kerrie Unsworth, "Unpacking Creativity", Academy of Management Review, Vol. 26, No. 2, pp. 286-297, 2001.

[66] K. Sarri, I. Bakouros and E. Petridou, "Entrepreneur Training for Creativity and Innovation", Journal of
European Industrial Training. Vol. 34, No. 3, pp. 270-288, 2010.

[67] S. Chlosta, H. Patzelt, S.B. Klein and C. Dormann, "Parental Role Models and the Decision to become Self-Employed: The Moderating Effect of Personality", Small Business Economics, Vol. 38, pp. 121-138, 2012.

[68] E. Schmitt-Rodermund, "Pathways to Successful Entrepreneurship: Parenting, Personality, Early Entrepreneurial Competence, and Interests", Journal of Vocational Behavior, Vol. 65, pp. 498-518, 2004.

[69] Joseph Alois Schumpeter, "The Theory of Economic Development: An Inquiry into Profits, Capital, Credit, Interest and the Business Cycle", Transaction Publishers, 1934.

[70] C.E. Shalley, J. Zhou and G.R. Oldham, "The Effects of Personal and Contextual Characteristics on Creativity: Where Should We Go From Here?", Journal of Management, Vol. 30, pp. 933-958, 2004.

[71] S. Shane and S. Venkataraman, "The Promise of Entrepreneurship as a Field of Research", Academy of Management Review, Vol. 25, No. 1, pp. 217-226, 2000.

[72] G. Singh and A. DeNoble, "Views on Self-Employment and Personality: An Exploratory Study", Journal of Developmental Entrepreneurship, Vol. 8, No. 3, pp. 265281, 2003.

[73] J. Sternberg and T. Lubart, "The Concept of Creativity: Prospects and Paradigms", Cambridge University Press, 1999.

[74] E.T. Stavrou and P.M. Swiercz, "Securing the Future of the Family Enterprise: A Model of Offspring Intentions to Join the Business", Entrepreneurship Theory and Practice, Vol. 23, No. 2, pp. 19-39, 1998. 